\title{
The Human Impact on the Emergence of Firm Supply Chain Agility: A Multilevel Framework
}

\author{
Ismail Gölgeci (corresponding author) \\ Dr., Associate Professor of Marketing Strategy, School of Business and Social Sciences, \\ Department of Business Development and Technology, Aarhus University, Birk Centerpark 15, \\ Building 8001, 7400 Herning, Denmark. E-mail: i.golgeci@btech.au.dk
}

\begin{abstract}
Abderaouf Bouguerra
Dr., Postdoctoral Researcher, Department of Accounting, Copenhagen Business School, Solbjerg Plads 3, 2000 Frederiksberg, Denmark. E-mail: abo.acc@cbs.dk

Yasin Rofcanin

Dr., Reader of Organizational Behavior and Human Resource Management, University of Bath, School of Management, Bath, UK. E-mail: y.rofcanin@bath.ac.uk
\end{abstract}

Purpose- The human element, especially its multilevel manifestation, has been overlooked in research investigating the antecedents of firm supply chain agility (FSCA). Our purpose is to explore how a firm's entrepreneurial orientation and market orientation affect FSCA through individual capabilities and actions within the boundary conditions of individual identification with the firm and organizational work climate.

Design/methodology/approach- Following a multilevel approach and drawing on a crossdisciplinary reading of the literature, we analyze drivers and enablers of FSCA and advance a framework explaining the emergence of FSCA within the boundary conditions of transformational leadership, individual identification and organizational work climate.

Findings- We advance that relevant individual capabilities and intraorganizational actions underlie FSCA in the firms' pursuit of realizing their strategic orientations as increased agile capacities. The effectiveness of individual capabilities and actions for the emergence of FSCA is contingent upon the extent to which managers identify themselves with their firm, transformational leadership, and the nature of organizational work climate.

Originality- The original contribution of our paper is to explain the interplay between the multilayered attitudinal, behavioral, and structural enablers of FSCA and incorporate the human element into the research on the antecedents of FSCA.

Keywords: Firm supply chain agility; multilevel research; entrepreneurial orientation; market orientation; identification; organizational work climate 


\section{Introduction}

Firms rely on strategic orientations to allocate their resources and develop and deploy their capabilities to achieve desired ends (Hakala, 2011; Schweiger et al., 2019). Their human capital resources within and across their boundaries are pivotal elements in their pursuit (Christopher, 2000; Doz \& Kosonen, 2010). A firm's supply chain agility (FSCA) is particularly important to create and capture value in a nimble and dexterous way in today's complex and dynamic global marketplace (Braunscheidel \& Suresh, 2009; Gligor, Holcomb, \& Feizabadi, 2016; Swafford, Ghosh, \& Murthy, 2006). Simply referring to the firm's strategic ability to respond quickly to unexpected or rapid changes in demand and supply in its supply chain, FSCA is driven by relevant strategic orientations (Gligor et al., 2016) and has a high potential to explain competitive value creation in volatile environments (Christopher, 2000).

However, despite the promising growth of the FSCA construct, it has not been sufficiently explored through human resource management (HRM) perspective (Blome, Schoenherr, \& Rexhausen, 2013; Braunscheidel \& Suresh, 2009; Swafford, Ghosh, \& Murthy, 2008), and underlying means of translating strategic orientations into FSCA have not been explored. Past research has typically examined FSCA at a single level, ignored multilevel factors, and overlooked human dimension. Firm-level relationships are not mechanistic but underlain by individual means as microfoundations (Carmeli et al., 2017), and firm-level capabilities are the aggregation of individual-level capabilities (Coleman, 1990; Felin \& Foss, 2005). The oversight of this central notion in extant research has resulted in limited explanations of the behavioral means through which FSCA emerges.

Drawing on the recent developments on FSCA concept and HRM research and the identified gaps, we aim to bridge HRM and FSCA by emphasizing the human element. In particular, we explore how a firm's entrepreneurial orientation (EO) and market orientation (MO) 
as two relevant strategic orientations (Hakala, 2011; Schweiger et al., 2019) affect FSCA through individual capabilities and actions within the individual-level and firm-level boundary conditions. The core premise of this paper is that while FSCA influenced by the key strategic orientation of entrepreneurial orientation and market orientation at the firm level, unique individual capabilities and actions underlie FSCA at the individual level within the boundary conditions of transformational leadership, individual identification with the firm, and organizational work climate. As such, because FSCA is ingrained in human behavior, exploring the multilevel behavioral antecedents of FSCA is necessary to advance its understanding. Such exploration can elucidate the behavioral means through which FSCA emerges and multilevel boundary conditions that shape such means.

By incorporating both supply chain management (SCM) and human resource management (HRM) insights into the study, the paper offers how HRM lens can inform the study of individual and organizational agility and opens a new line of research in organizational behavior and HRM for advancing the behavioral understanding of agility. It helps bridge the gap between HRM and SCM research by conceptualizing and examining individual agility in relation to SCM and building a framework of FSCA that includes relevant factors within the domain of HRM. As such, it contributes to both streams of research by developing an inclusive theoretical model on the multilevel determinants of FSCA in a pursuit to achieve a fine-grained understanding of FSCA.

\section{Theoretical background}

Firm supply chain agility and its antecedents

Agility has attracted increased attention particularly in operations management (OM) / SCM (e.g., Blome et al., 2013; Sharifi \& Zhang, 1999; Swafford et al., 2006) and information systems (IS) (e.g., Sambamurthy, Bharadwaj, \& Grover, 2003). Earlier research on agility concentrated on operational processes (see Table 1). Nonetheless, especially its later conceptualizations and examinations elevated 
agility to a holistic and strategic level, due to its extensive applicability and high importance (Doz \& Kosonen, 2010) and its enabling role in integrating diverging strategic objectives, i.e., focus and adaptability, commitment and flexibility (Di Minin et al., 2014). Such a transformation of the understanding of agility phenomenon brought about an increased relevance of HRM, a promoter and executor of firmwide policies, to study agility. Hence, as agility has been increasingly viewed as strategic, the role of strategic HRM in maintaining firmwide structure and mechanisms to develop and deploy agility has become an interesting phenomenon to investigate (Carmeli et al., 2017).

FSCA refers to the firm's ability to quickly adjust its strategies, structures, and activities within its boundaries and supply chain to internal and external changes (Gligor \& Holcomb, 2012a). These changes could be opportunities, challenges, or threats. FSCA is a strategic ability to adapt and accommodate quickly unplanned and sudden changes in opportunities and pressures stemming from a rapidly changing global marketplace (Tsourveloudis \& Valavanis, 2002). FSCA is the agility of the firm's value creation through upstream and downstream processes conducted collaboratively within and across organizational boundaries. Thus, though the firm's own activities and resources are at the epicenter of FSCA, mobilizing supply chain relations and resources are also crucial for achieving FSCA and sometimes could make a competitive difference (Christopher, 2000; Gölgeci, Murphy, \& Johnston, 2018). To survive and flourish in uncertain, complex, and changing environments, firms must be agile in managing their supply chains (Prater, Biehl, \& Smith, 2001).

Most past studies on FSCA developed arguments for the role of FSCA in competitive advantage (e.g., Christopher, 2000), measurement of FSCA (e.g., Van Hoek, Harrison, \& Christopher, 2001), clarification of (e.g., Gligor \& Holcomb, 2012b), antecedents of (e.g., Braunscheidel \& Suresh, 2009), and consequences of FSCA (e.g., Yusuf et al., 2004). However, 
despite such extensive research on agility and FSCA, micro-level behavioral phenomena as underlying means to explain agility have been ignored. Most studies investigating agility concept have done at either firm or supply chain level and overlooked human touch on agility concept, although agility is exercised by people then aggregates into the firm level.

Augier and Teece (2007) notice several major aspects affecting firms' capabilities, i.e., characteristics of managers or owners, firm architecture, and turbulent business environment. When applying these insights to the case of the FSCA, the key components outlining FSCA would be a) characteristics and actions of the firm's managers and b) organizational architecture aspects that denote the firm's behavioral and structural features. The relevance of strategic HRM to FSCA becomes evident once these two key aspects that shape FSCA are captured. HRM policies and practices can influence individual attitudes and actions (Lengnick-Hall, Beck, \& Lengnick-Hall, 2011). In particular, agility requires that managers at all levels, especially those who span organizational boundaries, engage in proactive, adaptive, and generative behaviors, bolstered by a supportive mindset and HRM policies (Dyer \& Shafer, 2003). Accordingly, the question of how FSCA is underpinned by and manifested at the firm level through managers' capabilities and actions could significantly benefit from strategic HRM research.

Table 1 shows that antecedents of FSCA are often argued to be firm-level variables such as integration, coordination, customization, visibility, market and learning orientation, and proactive and reactive strategy making among many others (see e.g., Braunscheidel \& Suresh, 2009; Gligor \& Holcomb, 2012a; Sharifi \& Zhang, 1999; Swafford et al., 2006). The wide variety of antecedents of FSCA illustrates that there might be many routes to foster, achieve, and sustain FSCA. Nonetheless, it also shows that the research on the antecedents of FSCA is fragmented, mainly along the lines of research following IS and OM/SCM domains, and often ignores the 
human element. Despite a plethora of antecedents considered and a broad range of issues included, any overlaps that could be observed in this line of research typically reside within IS and OM/SCM domains, rather than across them.

\section{Insert Table 1 here}

In short, despite extensive research and breadth of factors considered antecedents of FSCA, individual capabilities and actions that underlie the multilevel determinants of FSCA has been largely unnoticed in extant research. Likewise, OM/SCM and IS research typically focused on particular activities or elements as antecedents of agility. An overarching view of individual capabilities and activity archetypes has been missing in these research streams. Nonetheless, firms are not the collections of rational agents and mechanistic systems. Rather, they are behavioral systems of value creation, and their members are malleable human beings. In this study, we address this major gap by focusing on broadly applicable individual capabilities and managerial activities embedded in the firms' organizational environment as contingent microfoundations of FSCA.

\section{Individual underpinnings of FSCA}

We discuss individual agility as a microfoundational capability that aggregates at the firm level through interaction between managerial processes and organizational environment. Individual agility refers to capability and readiness to rapidly or inherently embrace and respond to change flexibly via high-quality relationships with the environment (Conboy \& Fitzgerald, 2004). An agile individual is capable of meeting technological and market challenges, learning in teams, and dealing with amplified complexity (Plonka, 1997). Individual agility is multidimensional. Perceptivity, decisiveness, flexibility, and swiftness (Gligor, 2013) are salient dimensions of individual agility and are discussed further below. These four dimensions complement each other to reflect the defining characteristics of agile managers; as perceptivity and decisiveness refer to both cognitive and emotional abilities, and swiftness and flexibility refer to physical 
abilities(Gligor, 2013). While the cognitive and emotional domain represents the potential of agility as a person's agility driving aptitude and behavior, the physical domain represents the realization of agility through its manifestation.

First, individual perceptivity refers to be being constantly aware of the environment and being prepared to face unexpected challenges and opportunities. Individuals' perceptivity can open the gate for and undergird organizational learning. It is an integral part of agility and becomes especially critical when the environment is unpredictable (Sambamurthy et al., 2003). Perceptivity facilitates identifying and leveraging opportunities and allows alleviating the waste of resources when facing sudden and drastic positive or negative change due to its enabling role in readied responses (Gaglio \& Katz, 2001). Thus, a manager's perceptivity and sensitivity to external factors are critical to realizing agility.

Second, individual decisiveness refers to the ability to make decisions resolutely (Gligor, 2013), and also manifests emotional attachment and commitment to the firm. It is the second cognitive and emotional dimension of agility (Gligor, 2013). Agility is dependent on the ability to show positive commitment towards the firm and make effective and resolute decisions in dynamic environments using the available (even if limited) information. Without making conscious and conclusive decisions and exhibiting commitment, individual may not act appropriately and may face the danger of losing their direction and control in dynamic environments. Decisive and committed individuals can proceed accordingly against external changes (Gligor, 2013). Consequently, individuals may not be fully agile if they are not decisive and fully committed, since resolute decision-making is a priori requirement for taking necessary actions.

Third, individual flexibility refers to the ability to adjust behavior to cope with changing circumstances in the work environment. Agile individuals are flexible to meet changing work and 
external requirements and face volatile supply-demand markets (Prater et al., 2001; Swafford et al., 2006). Such flexibility may be manifested in working hours, job descriptions, placement, and travel adjustments. As firms are moving away from mass-production and standardization to agile manufacturing and customization (Gunasekaran, 1999), individuals who can adapt and respond to changes enable firms to reconfigure and redeploy their capabilities and resources without overstretching or falling behind.

Finally, agile individuals are quick at making decisions and taking actions (Conboy \& Fitzgerald, 2004; Li et al., 2008). Individual swiftness refers to the timeliness of decision-making or performing an activity. Swiftness is not about hectic or feverish work tempo but about being nimble whenever necessary. The importance of swiftness for agility cannot be overstated (Conboy \& Fitzgerald, 2004). Though swiftness alone cannot define agility, it enables individuals to meet the realities of dynamic environments in a timely manner.

In summary, we conceptualize individual agility as a capability consisting of four salient dimensions and underlying FSCA at the firm level. In this way, we deviate from past research on FSCA and offer an improved micro-level understanding of how FSCA arises.

\section{Theory development}

Most management issues involve multilevel phenomena, involving individuals and the broader organizational environment in which individuals are embedded (Lee \& Idris, 2017; Ohana, 2014). Thus, methodological individualism highlights the need to explain macro-level phenomena via individual-level factors to prevent flaws and contradicting explanations (Felin \& Foss, 2005). Although one macro-level issue seems to be influencing the other macro-level issue, their relation can be only explained through the transition of macro-micro-macro level forces (Coleman, 1990). "Since the system's behavior is, in fact, resultant of the actions of its component parts, knowledge of how the actions of these parts combine to produce systematic behavior can be expected to give 
greater predictability than statistical relations of surface characteristics of the system" (Coleman, 1990 p. 3). This implies that analysis of conditions of individual actions, upon which individuals (i.e., managers) act and are partly influenced by the macro(firm)-level forces (Felin \& Foss, 2005), helps explain underlying and sometimes subtle means of macro-level phenomena.

Managers view the firm and its characteristics according to their own perceptions (e.g., identification with the firm) and values. Thus, firm-level antecedents have a contingent influence on managers and their actions and capabilities. Drawing on this premise, we argue that FSCA emerges from managers' capabilities and actions (especially that of boundary-spanning managers) driven by the firm's strategic orientations on a contingent basis. This argument highlights that firms cannot be analyzed independent of managers, and supposed relationships between firm-level phenomena indeed function via individual-level phenomena.

Following the logic of Coleman's (1990) work, Figure 1, 2, 3, and 4 depict our theoretical framework and illustrate the attitudinal and behavioral paths feeding the emergence of FSCA. Managers' capabilities and actions have an underlying effect on organizational capabilities and activities (Wright \& Mcmahan, 2011). They shape the strategy, tactics, and everyday activities of their firm. More importantly, the capabilities of firms are rooted in the member-managers of these systems, as there is no other entity than people to manifest such capabilities. Thus, FSCA is dependent on the skills and capabilities of managers working in the firm. Below, we delve deeper into how managers' specific agile capabilities and actions convert key strategic orientations of EO and MO into increased FSCA. We argue that managers who are alert to their environment, decisive in their actions in the face of change, flexible with workload and tasks they overtake, and nimble at decision-making and taking actions are the primary sources of FSCA. We then introduce individual and organizational contingencies that fashion the nature of the linkages discussed 
below. We provide boundary conditions for our framework and argue that organizational work climate and individual identification with the firm can facilitate the emergence of FSCA.

\section{The emergence of FSCA}

Strategic orientations. Our framework draws on the central notion that strategic orientations function as an attitudinal basis and direction for managerial decision-making and action (Hakala, 2011; Schweiger et al., 2019). The crux of the word orientation means a lasting direction of thought, inclination, or interest that define managerial attitudes (Hakala, 2011; Rauch et al., 2009). In a business context, strategic orientations are the overarching logic in guiding business actions (Wei \& Lau, 2005). They shape how capabilities are built and manifested. Thus, relevant strategic orientations could stimulate FSCA in the face of rapid change, elusive fields of opportunities and threats, and hypercompetitive markets that are products of a multitude of choices available to sophisticated customers. They can, for example, play a pivotal role in promoting agile capabilities and actions of the firm's managers through such mechanisms as attracting, motivating, and mobilizing managers to realize the guiding principles of strategic orientations (Wei \& Lau, 2005).

Likewise, strategic orientations can be communicated to relevant managers through internal marketing efforts and intraorganizational communication mechanisms that help infuse firms' strategic orientations into the managerial mindset. Once a given strategic orientation takes hold among relevant pioneer managers, it may fast diffuse across other managers within the firm. Accordingly, the firm's vital strategic orientations can have a defining influence on its FSCA.

We argue that two central strategic orientations that lay the ground for development and deployment of capabilities leading to FSCA are EO and MO (Gligor et al., 2016; Zahra, Sapienza, \& Davidsson, 2006). EO refers to the firm's disposition to accept and adopt entrepreneurial processes, practices, and decision-making activities that lead to the development of new and distinctive value offerings (Lumpkin \& Dess, 1996). Entrepreneurially-oriented firms are attentive to 
their environment, determined and swift in responding to opportunities (Rauch et al., 2009), and effectual in converting vision into reality. Speed, flexibility, and decisiveness as attributes of FSCA are also central to entrepreneurial behavior (Lumpkin \& Dess, 1996). Entrepreneurially-oriented firms are effective in utilizing opportunities and thriving in tumultuous environments. Thus, EO can be a salient attitudinal criterion for developing FSCA (Nijssen \& Paauwe, 2012; Teece, 2014).

$M O$ refers to the firm's disposition that triggers the necessary behaviors for the creation of superior value for buyers (Narver \& Slater, 1990). The current research views FSCA as a strategic capability resulting from MO (Gligor et al., 2016). Customer orientation, competitor orientation, and interfunctional coordination as core components of $\mathrm{MO}$ are essential ingredients for developing and deploying agility across the firm's supply chain. Likewise, $\mathrm{MO}$ is a rare attitudinal resource which, when deployed in combination with other resources, can contribute to the development of a unique set of capabilities that can give rise to a positional advantage for firms (Gligor et al., 2016). Due to its external focus prioritizing boundary spanning strategy and activities and organizational learning through partners (Min, Mentzer, \& Ladd, 2007), MO can be a pivotal underlying disposition for FSCA. Furthermore, MO is a strategic tool that steers the development of processes and capabilities that respond to customers' explicit and latent needs (Narver \& Slater, 1990). Thus, as a source of firmwide market intelligence (Kohli \& Jaworski, 1990), MO uniquely fosters FSCA to provide a real-time response to customers' unique and changing needs.

Firms can have a plethora of different strategic orientations due to different priorities and goals in different times and environments. Some strategic orientations such as EO, MO and learning orientation have a central and universal position within firms (Schweiger et al., 2019); while others such as risk orientation, supply chain orientation, or team orientation represent domain-specific or peripheral strategic orientations. As we are interested in how critical firm strategic orientations lead to FSCA, we posit that EO and $\mathrm{MO}$ are distinctly relevant to individual agile capabilities due to the premises of $\mathrm{EO}$ (Lumpkin \& Dess, 
1996), MO (Kohli \& Jaworski, 1990), and FSCA (Braunscheidel \& Suresh, 2009; Gligor et al., 2016). First, as EO is about alertness, autonomy, opportunity seeking and leverage, and nimbleness (Gaglio \& Katz, 2001; Lumpkin \& Dess, 1996), entrepreneurial firms are more likely to develop agile capabilities and structure. Second, MO entails external focus, organizational learning, and adaptability (Min et al., 2007; Narver \& Slater, 1990), all of which are essential to maintaining agile workforce and organizational structure (Nijssen \& Paauwe, 2012). As a result, EO and MO are deemed particularly relevant for FSCA among salient strategic orientations.

Nonetheless, the potential influences of EO and MO on FSCA would not just occur in a mechanistic or wholesale fashion, independent of the people working in their respective organizations. Instead, these influences involve managerial processes through relevant individual capabilities and actions for the emergence of FSCA. Thus, while the firm's strategic orientations can play a stimulating role in managers' agile capabilities and actions, individual capabilities and actions, in turn, can play an underlying role in translating strategic orientations into increased FSCA.

Sensing and discerning opportunities and threats. We argue that both EO and MO could be central forces for fostering capabilities and actions for the detection of market signals by boundaryspanning managers. MO promotes individual behaviors to create value for customers (Wei \& Lau, 2005). A market-oriented firm makes efforts to satisfy customer needs through mobilizing appropriate individual behaviors such as listening to customers effectively. Likewise, as alertness is an integral element of EO (Lumpkin \& Dess, 1996), entrepreneurially-oriented firms are likely to employ organizational and HRM policies that promote perceptivity to internal and external signals by their managers. Thus, managers working in market- and entrepreneurially-oriented firms can enjoy organizational environments where perceptivity capability is promoted and supported. 
As stated above, sensing and discerning external threats and opportunities is a crucial precondition for effective agile action. If a person is not able to read external signals on a continuous and accurate basis, her/his reactions could be either too slow or erratic to sustain genuine agility. This is especially relevant to boundary-spanning managers who link firms with their external environment (Ryan \& O'malley, 2016). As such, perceptivity forms the ground of the managerial actions of sensing and discerning environmental change, and opportunity identification could be viewed as the manifestation of perceptive capabilities (Gaglio \& Katz, 2001).

The firm's ability to sense external opportunities and threats can be grounded in the managers' perceptivity and ensuing activities of identifying opportunities and risks facing the firm and its supply chain. In so doing, (boundary-spanning) managers rely on relationships with external agents and interorganizational information flow that follows (Ryan \& O'malley, 2016). As the detection and identification of such internal and external changes are distinct behaviors, the aggregation of such behaviors by managers at the firm level is expected to be rather smooth especially when internal knowledge transfer is rooted in inter-functional coordination (Kohli \& Jaworski, 1990; Narver \& Slater, 1990). However, if managers are not perceptive to the environment and not good at opportunity identification, the firm's capacity to sense external opportunities and threats could be curtailed. Thus, as shown in Figure 1, we propose:

Proposition 1a. Entrepreneurial orientation and market orientation of the firm affect managers' perceptivity that, eventually, determine their sensing and discerning opportunities and threats.

Proposition 1b. The firm's capacity to sense external opportunities and threats emerges as a function of managers' perceptivity through sensing and discerning opportunities and threats. 
Resolute decision-making and implementation. The nature and processes of decisions are an essential element of entrepreneurship (Zahra et al., 2006). As a distinct logic of the firm, EO provides the basis for entrepreneurial decisions (Rauch et al., 2009). Managerial decisions in dynamic and unpredictable external environments particularly involve risk-taking and the allocation of scarce resources (Rauch et al., 2009). They, therefore, serve their function best when supported by EO. In particular, as autonomy is a salient dimension of EO (Lumpkin \& Dess, 1996), entrepreneurially-oriented firms can encourage and mobilize autonomous decision-making. Accordingly, decisive managers who can take initiatives and make resolute decisions are more supported in entrepreneurially-oriented firms.

Individual decisiveness could be viewed as a multifaceted cognitive capability. On the one hand, it could be a source of swift, resolute, and effective managerial action in the face of sudden or rapid environmental change. On the other hand, it could also be a source of blinded, erratic, and sometimes irreversible actions. However, on the whole, we posit that decisiveness is more likely to be a positive source of managerial actions that underlie FSCA than vice-versa, especially under an external environment that that is hypercompetitive and dynamic (Di Minin et al., 2014) and an organizational environment that is entrepreneurial, equitable, and supportive of educated autonomy (Lumpkin \& Dess, 1996; Rauch et al., 2009).

A firm's capacity to respond to environmental changes represent "the moment of truth" of FSCA, i.e., a physical manifestation of agile capabilities (Braunscheidel \& Suresh, 2009; Gligor, 2013). Without responsive capacity, firms may, despite being alert and swift, unable to respond to a drastic change in murky environments. However, a firm that has managers making resolute decisions in the face of sudden changes can harvest the fruits of their alertness and speed and avoid 
being not responsive despite being alert. In the end, firms' capacity to respond emerges through individual decisions of its managers. Therefore, as shown in Figure 2, we propose:

Proposition 2a. Entrepreneurial orientation of the firm affects managers' decisiveness that, eventually, determine their resolute decision-making and implementation.

Proposition 2b. The firm's capacity to respond to environmental changes emerges as a function of managers' decisiveness through resolute decision-making and implementation.

\section{Insert Figure 2 here}

Resource configuration and deployment. FSCA entails making quick adjustments in and reconfiguration of the resource base to flexibly respond to varying customer demands (Swafford et al., 2008). Thus, MO is particularly relevant to individual flexibility dimension of agility (Gligor et al., 2016). Customers and value creation are at the epicenter of market-oriented firms (Narver \& Slater, 1990), and such logic both promotes and reinforces flexibility toward various and changing customer needs (Min et al., 2007). Emergent market forces have pushed firms to operate with less authority and allow and promote flexibility, responsiveness, and learning (Teece, 2014). Market-orientated firms tailor HRM practices to induce flexibility in configuring and deploying resources to customer's ends to facilitate the attainment of strategic goals (Wei \& Lau, 2005). Thus, MO could be an essential basis for managers to flourish their flexibility.

An agile manager is capable of meeting technological and market challenges, designing work, learning in teams, and dealing with increased complexity (Plonka, 1997). Drawing on the notion that these behavioral elements could be intangible resources (Wright \& Mcmahan, 2011), flexibility arises as an essential capability in shaping their allocation and configuration. Flexible managers can adjust their speed and extent of supply chain activities by configuring their resource basis and deploying the right resources for the right purposes. Though flexibility itself may come 
at a cost (Zahra et al., 2006), its fosters managers' adaptive configuration and deployment of relevant resources of the firm (Teece, 2014).

Market-oriented firms can harvest their efforts of promoting and reinforcing individual flexibility as an increased organizational capacity to bend their organizational and supply chain resources and structure as a response to market heterogeneity. For example, by taking advantage of an agile workforce, a firm may be able to respond quickly to unexpected workloads that may arise due to a sudden increase in demand or disruption in supply (Tsourveloudis \& Valavanis, 2002). Relying on flexible managers who can readily stretch their boundaries and are skillful in resource combination for value creation, firms can shape their structure and resource deployment in a smooth and malleable way. Likewise, boundary-spanning activities can enable firms to tap rare and valuable external resources and give greater room for innovative resource configuration and deployment (Ryan \& O'malley, 2016). Thus, as shown in Figure 3, we propose:

Proposition 3a. Market orientation of the firm affects managers' flexibility that, eventually, determine their resource configuration and deployment.

Proposition 3b. The firm's capacity to bend organizational resources and structure emerges as a function of managers' flexibility through adaptive resource configuration and deployment. Insert Figure 3 here

Accelerating managerial actions. As technologies and socioeconomic forces evolve, people live in an increasingly accelerated world (Chakravarty, Grewal, \& Sambamurthy, 2013; Teece, 2014). Accordingly, nimble capabilities function as a facilitator both for effective implementation of entrepreneurial decision and strategies and flexible actions to satisfy varying customer needs. EO and MO-based organizational logics and guiding principles would lead firms to follow HRM policies toward attracting, selecting, motivating, and developing nimble managers (Wei \& Lau, 2005). 
Therefore, an organizational environment that sustains $\mathrm{EO}$ and $\mathrm{MO}$ could be more conducive to individual swiftness.

Especially under conducive conditions, one can expect that swift managers are better at accelerating their activities whenever necessary. They can apply their capabilities to their everyday actions toward meeting rapidly changing external demands and insights. As firms with EO and MO are open to change (Hakala, 2011; Min et al., 2007), swift managers working in such firms typically experience conditions that favor the manifestation of their capabilities in the form of accelerated managerial actions. Thus, we argue that swiftness forms the attributive ground upon which accelerated managerial actions underlie FSCA.

No matter how alert, responsive, and flexible, firms cannot be qualified as genuinely agile unless they put their strategies for value creation into actions in a timely manner. As they actually compete against time, firms need to command the speed of their strategies and processes (Eisenhardt, 1989). However, such control over the speed of organizational tactics and SCM operations do not occur in a mechanistic fashion. Individual actions serve as microfoundations to firms' capacity to control the speed of their tactics and operations, especially when they work in harmony (Plonka, 1997). The emergence of such capacity is contingent upon how managers adjust the speed of their managerial actions as a part of organizational processes. Thus, as shown in Figure 4, we propose:

Proposition 4a. Entrepreneurial orientation and market orientation of the firm affect managers' swiftness that, eventually, determine their acceleration of managerial actions.

Proposition $4 \mathbf{b}$. The firm's capacity to control the speed of tactics and operations emerges as a function of managers' swiftness through accelerating managerial actions.

The moderating role of transformational leadership, identification, and organizational work climate 
A vast body of literature recognizes that individual and organizational phenomena cannot be fully understood independent of each other (e.g., Alfes et al., 2013; Felin \& Foss, 2005; Kwon, Farndale, \& Park, 2016; Lengnick-Hall et al., 2011; Plonka, 1997; Wright \& Mcmahan, 2011). Therefore, the organizational environment and the managers' perception of it can shape the nature of the ties between strategic orientations and FSCA. As human resource strategy is argued to be pivotal to foster the successful attainment of agility (Shafer et al., 2001), leadership, (i.e., transformational leadership), individual (i.e., identification) and organizational (i.e., organizational work climate) forces could shape how strategic orientations drive individual capabilities and how FSCA emerge through individual actions. Managers' capabilities and actions are embedded in and can be fashioned by the organizational environment. Transformational leadership, individual identification, and organizational work climate can be sources of motivation and opportunities to foster individual capabilities and accumulate managerial actions into enhanced firm-level capacity (Gabriel et al., 2016). Consequently, we scrutinize the moderating effect that transformational leadership, individual identification, and organizational work climate may have on the emergence of FSCA.

A manager's leadership style within a firm is crucial to explain work behavior and attitude. Specifically, transformational leadership style aims to create emotional links with employees and inspires higher values to shape capabilities and ensuing behaviors. Such leadership style translates into having a shared vision and establishing a sense of purpose, direction and meaning within the firm (Bass, 1999). Accordingly, a transformational leader or manager is likely to be committed to the firm's goals and further influences employees to integrate and implement the business vision and strategy successfully (Avolio et al., 2004). 
Transformational managers exhibit four primary behaviors. Firstly, managers establish and convey a shared vision and high expectations that are motivating, inspiring, and challenging employees. Secondly, transformational managers tend to influence employees in ways that are consistent with the firm's strategic orientations. Thirdly, transformational managers intellectually stimulate employees to challenge existing ideas. Finally, transformational managers tend to meet the needs of their employees and treat each employee as a unique individual; hence these managers foster feelings of trust and nurse commitment among employees (Wang et al., 2011).

Taken together, these transformational leadership behaviors are expected to motivate employees and engage in complex activities and perform at higher levels. These leadership behaviors also promote employees' creativity, knowledge, and learning so that employees can find innovative ways to problem solving and solutions (Garcia-Morales, Matias-Reche, \& HurtadoTorres, 2008).

When managers adopt a transformational style within the firm, they are likely to influence employees to embrace a shared vision in ways that are in line with the overall business strategy. Moreover, these managers are likely to adopt and convey their firms' strategic orientations and implement them adequately. Also, through motivating and engaging employees and promoting their creativity and learning, these employees can find efficient ways to integrate and execute operational and strategic processes.

One of the main benefits of transformational leadership is translating EO and MO into individual capabilities. The core argument here is that transformational managers play a pivotal role in converting $\mathrm{EO}$ and $\mathrm{MO}$ into mico agile capabilities via influencing and motivating employees to realize the firm's strategic orientations. The effect of the firm's EO and MO on individual agile capabilities is significant when managers use transformational leadership style to 
implement and convey strategic orientations within the firm. The main strengths of transformational leadership lie on the fact that managers comprehend the main business strategy, procedures, and processes and are likely to influence employees to follow and implement them smoothly. Additionally, through enhancing learning and creativity by transformational managers, employees can develop a set of capabilities that suit the firms' strategic orientation. In a similar vein, transformational managers are tied to the firm's goals and are aware of how these orientations can be conveyed to employees at all levels within the firm (Huo et al., 2016). Hence, firms with EO and MO further develop individual agile capabilities when their managers adopt a transformational style.

An organization with transformational managers acquires and develops adaptive and flexible practices better than their counterparts. These managers can persuade the workforce to be more engaged in developing capabilities and executing actions, and also implementing an organization strategic orientations (Bass et al., 2003). For instance, transformational managers transform the self-concepts to the employees. They build personal and social identification among employees with the mission and goals of the manager and organization. This, in turn, nurtures employees' feelings of involvement, cohesiveness, commitment, and potency to operationalize efficiently organizational vision and mission (Shamir, House, \& Arthur, 1993). Also, transformational managers seek to build collective confidence or potency required for employees to deal successfully with difficult situations and challenges. This includes challenges that emerge in the supply chain of a firm. In this vein, leadership actions that influence and develop employees interpersonal and problem-solving skills is a critical determinant of collective efficacy to manage the supply chain without any disruption or risk (Zaccaro et al., 1997). The above discussion leads to the following proposition: 
Proposition 5. The extent of managers' transformational leadership strengthens the linkages between the firm's strategic orientations of market and entrepreneurial orientation and managers' agile capabilities of perceptivity, decisiveness, flexibility, and swiftness.

A manager's identification with the firm s/he works is a significant factor to examine concerning work behavior and engagement (Alfes et al., 2013; De Ruiter et al., 2016). Manager's organizational identification is about role recognition and managers' feeling of belonging to their firm (Ashforth \& Mael, 1989). It influences how a manager acts within the firm and interacts with other managers. It relates to belief in and dedication to a firm's norms, orientations, values, and a willingness to exert extra effort for a firm (Huo et al., 2016). A manager's identification inherits the psychological aspect in explaining the relationships between the individual and the organization, as an essential aspect of organizational behavior (Van Knippenberg \& Schippers, 2007).

Whether managers identify themselves with their organizations can have important implications for managerial behaviors (De Ruiter et al., 2016). However, managers', particularly that of boundary-spanning managers', identification with the firm is not guaranteed. Managers may feel they have to work in firms that they do not identify with due to various personal and professional reasons or may have confusing dual identities in the case of boundary-spanning managers (O'malley et al., 2014). Accordingly, firms cannot take their managers' identification for granted, and individual identification with the firms may play an essential role in the way managers take ownership of strategic orientations and follow them in building their capabilities.

When managers build a dedicated and robust identification to their firms, they are likely to accept their firms' orientations and adopt these orientations devoutly. They can internalize the orientations and priorities of their firm as if their own leading to faster diffusion of firms' strategic 
orientations within firms. For example, managers' sense of belonging and behaviors are unique in Apple (Scott \& Lane, 2000) that leads to the successful integration of demand management, supply management, and product management strategies. Firms can have several simultaneous strategic orientations as guiding mindsets and activity systems (Schweiger et al., 2019). Such multiplicity and potential paradox can incite sophistication that could be effective against environmental complexity, if it is coupled with strong individual identification with her firm.

A manager may, to a greater or lesser extent, conceive of themselves in terms of their psychological attachment to the organization. The magnitude of individuals' attachment to the organization triggers personal relationships and exerts an important influence on attitudes and behaviors (Van Dick et al., 2004). Such a psychological contract between individual and organization rests on the individual's beliefs for reciprocal obligations in exchange relationships. Prior research draws on two main perspectives to explain psychological relationships between the individual and the organization: the social exchange perspective (e.g., Rhoades \& Eisenberger, 2002; Rousseau \& Mclean Parks, 1993), and the social identity perspective (e.g., Ashforth \& Mael, 1989; Hogg \& Terry, 2000). Firstly, the central promise of social exchange perspective is built on the extent that employees and employer trade-off effort and loyalty; which is necessary and beneficial in terms of pay, support, and recognition (Rhoades \& Eisenberger, 2002; Rousseau \& Mclean Parks, 1993). As such, the quality of exchange relationship between the organization and its representatives (i.e., leaders and supervisors) is predictive of their changing attitudes and behaviors. Secondly, social identity perspective further explains employee-organization relationships through the notion that managers, to a greater or lesser degree, are self definitional (Ashforth \& Mael, 1989; Hogg \& Terry, 2000). Individuals may have the conception of the self in terms of "we" rather than "I" (Brewer \& Gardner, 1996). The extent to which individuals define 
themselves in terms of attachment is manifested in the concept of organizational identification. The core assumption here is that the more people identify with a group or organization, the more the group's or organization's interests are embedded in the self-concept, and thus the more likely that an individual expresses a positive attitude to act at the best interest of an organization (Dutton, Dukerich, \& Harquail, 1994; Van Knippenberg \& Van Knippenberg, 2005).

The strength of managers' identification with the firm can play an influential role in translating EO and MO into individual capabilities. The role of individual identification in converting EO and MO into enhanced individual agile capabilities can play out through increased individual interest and devotion to realize the firm's strategic orientations. The influence of the firm's EO and MO on individual capabilities could be stronger when managers identify themselves with their firm, and these orientations resonate with them. Managers who identify strongly with their organization are more likely to accept and follow their organization's guiding principles and norms (Ashforth \& Mael, 1989; De Ruiter et al., 2016) and invest in capabilities that suit their firms' strategic orientation. Likewise, such managers are intrinsically tied to the firm's established goals and are clearly aware of its orientations (Huo et al., 2016). Thus, firms with EO and MO may find it easier to promote and foster individual agile capabilities when their managers feel part of their organization and receptive to their policies. For example, the cognitive capabilities of perceptivity and decisiveness could be psychologically induced by a commitment to a firm that is maintained by strong identification (Sanders, Dorenbosch, \& De Reuver, 2008). Likewise, motivation, an essential component of work engagement and performance (Gabriel et al., 2016), can be reinforced by identification with the firm in the pursuit of fostering individual capabilities.

A firm composed of managers who identify with and feel part of their firm may be in a better position to mobilize and engage its workforce to realize its strategic orientations. As 
organizational identification and work engagement are positively intertwined (Alfes et al., 2013), managers who maintain strong connection and affinity to their firm would be more engaged in processes that foster their capabilities and actions. This includes interacting with supply chain partners. Managers maintaining strong identification to their firm could prioritize their firm's interests when interacting with supply chain partners (Scott \& Lane, 2000) and be more committed to leveraging their capabilities for utilizing supply chain resources swiftly. Thus, we propose:

Proposition 6. The extent of managers' identification with their organizations strengthens the linkages between the firm's strategic orientations of market and entrepreneurial orientation and managers' agile capabilities of perceptivity, decisiveness, flexibility, and swiftness.

Organizational work climate within the field of organizational behavior and psychology (Kuenzi \& Schminke, 2009) refers to the shared perceptions of the organization regarding practices, policies, procedures, routines, and rewards (Bowen \& Ostroff, 2004). It is the embodiment of the firm's organizational structure, people, and processes (Lee \& Idris, 2017). It is a firm-level phenomenon that reflects the shared values, belief systems, and perceptions of the majority of the workforce. It is a fundamental constituent of organizational environment and exhibits a pivotal influence on the way managers feel and work in their firm (Bowen \& Ostroff, 2004; Kwon et al., 2016). Likewise, organizational work climate is found to have a contextual effect on individual behaviors (Kao, 2017). For individuals within firms, organizational work climate takes the form of a set of attributes and expectancies that describe the overall pattern of organizational activities (Jaw \& Liu, 2003). It plays an essential role in shaping employees' behaviors and influencing their perception to execute actions and strategies (Chen \& Lin, 2004). In particular, organizational work climate also plays a considerable role in enacting and achieving harmony in the application of firmwide and HRM-related policies (Alfes et al., 2013). A robust 
organizational work climate functions as an aligning and unifying force for various individual capabilities and actions. Individual mindsets and behaviors are fostered by HRM policies centered on paradoxically stable guiding principles and anchored in a supportive and inclusive organizational work climate (Dyer \& Shafer, 2003). In that regard, organizational work climate could be an instrumental ingredient for the joint realization of the firm's alternative strategic orientations through individual actions.

The comprehensiveness of our framework may also depend on the organizational work climate of the firms to convert relevant strategic orientations into increased FSCA through individual capabilities and actions. The lack of a healthy organizational work climate that supports firmwide synchronization of resources, capabilities, and swift actions of managers can curtail translating individual actions and capabilities into the increased capacity of FSCA. In firms without supportive and unifying organizational work climate, one manager's agility could be another's bottleneck. Individual capabilities and actions can go in vain without alignment and firmwide adoption of the shared principles (Bowen \& Ostroff, 2004; Sanders et al., 2008). In particular, as organizational work climate supports the firm-wide application and realization of strategic orientations (Dyer \& Shafer, 2003), the underlying influence of individual capabilities and actions on FSCA would be more pronounced in firms with strong and pervasive organizational work climate that supports agility-driving managerial actions. A well-defined, coherent, and shared organizational work climate can provide opportunities to managers (Gabriel et al., 2016) for transforming their capabilities and actions into increased FSCA through activity synchronization and cohesive activity structures.

A shared and appropriately enacted organizational work climate can also help mobilize and coordinate individual actions in the pursuit of FSCA. A healthy organizational work climate can 
foster managers to be more engaged in their work and with their colleagues (Kwon et al., 2016) toward achieving necessary organizational capacities to compete in volatile environments (Christopher, 2000). Climate can be an essential precursor to SCM integration (Shub \& Stonebraker, 2009). Hence, organizational work climate can connect and bundle together various dimensions of individual agile actions provoked by alternative strategic orientations of EO and $\mathrm{MO}$ and jointly channeling them to give rise to FSCA. Moreover, organizational work climate can help boundary-spanning managers utilize supply chain relationships to foster FSCA, as a strong and cohesive internal work climate could enhance the firm's external image and relational advantage. Thus, we propose:

Proposition 7. A supportive and unified organizational work climate strengthens the linkages between the managers' agile actions and the firm's agile capabilities.

\section{Discussion and conclusions}

\section{Theoretical contributions}

Agile or not, many firms end up competing in highly dynamic, uncertain, and complex environments. In a tumultuous world, many firms stumble, and a few falls, often because the rate of external change outpaces their capacity to keep up (Dyer \& Shafer, 2003). Thus, agility needs to be at the epicenter of the firm's and its managers' internal compass to keep up with or outmaneuver rapid change (Braunscheidel \& Suresh, 2009; Doz \& Kosonen, 2010; Nijssen \& Paauwe, 2012). Such salience of FSCA concept for contemporary businesses entails a comprehensive and well-rounded understanding of its true drivers and enablers within an intraorganizational environment.

Four themes constitute the core premises and contributions of this paper. First, we advance the conversation between HRM and SCM. Scholars have just recently started to pay attention to the HRM-SCM interface (Carmeli et al., 2017; Shub \& Stonebraker, 2009). We argue that both 
HRM and SCM can benefit from further interaction and achieve profound insights into some puzzling phenomena that could not be fully understood using a single lens or approach. In particular, any phenomena that require both a systems approach and boundary-spanning nature of SCM and human touch of HRM can benefit from the cross-pollination of HRM and SCM research. Our paper offers a distinctive contribution to HRM and SCM research by building a comprehensive and multilevel framework of FSCA for further research.

Second, we put forth EO and MO as two critical attitudinal triggers to achieve FSCA. Despite extensive research that puts strategic orientations as pivotal drivers of firm behavior and structure (Hakala, 2011; Schweiger et al., 2019), scant and only recent attention has been paid to them as antecedents of FSCA (Gligor et al., 2016). Especially novel is our inclusion of EO as a potential firm-level driver of FSCA. We build this position based on the reasoning that agility and entrepreneurship share some common traits -particularly alertness and dynamism- that are unnoticed by the fragmented research on these central concepts (Gaglio \& Katz, 2001; Gligor, 2013; Rauch et al., 2009). The inclusion of EO expands the portfolio of strategic orientations that can trigger the emergence of FSCA. It also implies that EO and MO may complement each other when firms compete in dynamic and hypercompetitive environments where customers are increasingly powerful and sophisticated while the external environment is unprecedentedly turbulent.

Third, we explore multilevel behavioral means that explain the emergence of FSCA. Multilevel research has witnessed recent yet increased attention (e.g., Felin \& Foss, 2005; Kwon et al., 2016). We conceptualize FSCA as a multilevel collective capability emerging from the capabilities and actions of managers within firms. FSCA takes time and strenuous effort through path-dependent interactions to build at both individual- and firm-level. It involves strategic 
orientations that demand behavioral means to be realized. The paper shows how the management of managers in firms facilitates achieving FSCA. By introducing a multilevel research approach towards FSCA, the paper breaks from the past research that has predominantly examined the antecedents of FSCA at a single level. It aims to achieve a detailed understanding of the attitudinal drivers and behavioral enablers of FSCA and offers a broad view on what agility means at the individual level to develop a holistic and human-centered blueprint for achieving FSCA.

Fourth, we delve into transformational leadership, identification, and organizational work climate as instrumental contingent forces explaining the boundary conditions of FSCA. The inclusion of transformational leadership, individual identification, and organizational work climate shows that strategic orientations and individual agile capabilities and actions are not always sufficient in their own right for developing FSCA. The emergence of FSCA is contingent upon the extent to which managers adopt transformational leadership style and identify themselves with their firm to foster the development of individual agile capabilities as well as organizational work climate to channel individual agile behaviors toward an accumulation of FSCA. Thus, transformational leadership, individual identification, and organizational work climate all facilitate the realization of $\mathrm{EO}$ and $\mathrm{MO}$ jointly by mobilizing and harmonizing managers to make the best out of their potentials toward desired ends (Carmeli et al., 2017). In other words, transformational managers, individual identification, and organizational work climate can hold the keys to the successful transformation of strategic orientations and individual capabilities into the firmwide capability of FSCA. This position complies with a critical analysis of agility that highlights FSCA is not an immutable quality (Teece, Peteraf, \& Leih, 2016) but is bounded by contingencies. It also illustrates how HRM could be relevant for developing FSCA via a human-centered approach.

\section{Managerial implications}


Many firms happen to compete in highly dynamic, uncertain, and complex environments. Facing such external environment requires a holistic approach to develop strategic capabilities that could be deployed within and across firm boundaries. In particular, FSCA, as a change enabling the capability for creating greater value through supply chain operations, needs to be at the epicenter of the firm's and its managers' internal compass to keep up with or out-maneuver rapid change. Firms' human capital and supply chain partners can be leveraged to achieve FSCA that let firms to be alert, responsive, flexible, and nimble in the face of dynamism and volatility.

We argue that HRM and SCM can benefit from further interaction and achieve FSCA in a way that could not be sufficiently achieved following a confined approach. Because firms need greater internal interaction and collaboration to stay intact in the face of rapid change, FSCA can benefit uniquely from greater interaction between HRM and SCM. The management of individuals in firms to coherently mobilize their capabilities facilitates achieving FSCA. Therefore, HRM and SCM need to pay further attention to potential interplays and synergies between these functions to compete in turbulent times and environments (Nijssen \& Paauwe, 2012).

We believe that though strategic orientations of the firm can be an essential starting point for developing FSCA, its emergence largely depends on the effective manifestation and use underlying capabilities and actions of managers within the firm. In this vein, we introduce and discuss transformational leadership, individual identification, and organizational work climate as vital contingent forces explaining the boundary conditions of FSCA. We argue that the extent and the way managers adopt a transformational style, and also identify themselves with their firm conditions how EO and MO influence their agile capabilities. Likewise, organizational work climate can be aligning and unifying force behind flexible organizational structures and the individual actions leading to FSCA. Thus, firms are advised to formulate HRM policies to promote 
individual identification and support a favorable organizational work climate in order to steer rapid change.

\section{Suggestions for future research}

We propose an empirically testable theoretical framework. Nonetheless, as our framework is behavioral and covers complex social processes, explorative qualitative research could offer further and possibly fresh insights into the framework. Moreover, we draw on the assumption that nowadays, most firms face at least some degree of external dynamism and turbulence (Nijssen \& Paauwe, 2012). Nonetheless, not all dynamisms are the same. A "dynamism" faced in volatile regions and conflicts zones like Iraq, Nigeria, or Venezuela is not of the same nature a "dynamism" faced in highly-entrepreneurial and hyper-competitive settings like in the US, Hong Kong, or South Korea. Thus, a deeper insight into the role of different types of dynamism in necessitating and shaping agility is required for a contextual understanding of agility and its outcomes.

As the outcomes of FSCA are not covered in this study, an opportunity to examine our framework in relation to potential outcomes of FSCA could also be fruitful. Though numerous studies examined the performance outcomes of FSCA (e.g., Gligor \& Holcomb, 2012a; Jacobs et al., 2011; Liu et al., 2013), there is room for further research on performance-related and other outcomes of FSCA particularly in novel contexts and using new theoretical lenses such as institutional theory. Likewise, as some potential outcomes of FSCA such as survival are difficult to measure (mainly due to measurement challenges of failure (cf. Nijssen \& Paauwe, 2012)), new methodological approaches to the study of FSCA are needed.

Furthermore, beyond strategic orientations, it is possible that organizational culture may have an impact on the way FSCA developed and applied. One of the most well-known organizational culture framework, the competing values framework (CVF) developed by Cameron and Quinn (2011) articulates that organizational culture consists of four aspects: clan, adhocracy, 
market, and hierarchical culture, and that organizational culture is an indispensable element for organizational change. Accordingly, future research can adapt CVF to clarify whether organizational culture dimensions such as hierarchical culture and adhocracy culture also help develop FSCA.

Finally, we offer a theoretical framework drawing on HRM and SCM perspectives, and we are aware that conducting multilevel research is methodologically demanding due to such reasons as sampling, data collection, and analytical challenges of following multilevel research analytical tools like hierarchical linear modeling (HLM). However, multilevel research has been unforgivably overlooked, especially in the SCM field and is where "low-lying fruits" can be exploited. Hence, management, HRM, and SCM researchers should take a closer look at individual phenomena affecting firms and their supply chains. 
Table 1. Primary business and management research on the antecedents of agility.

\begin{tabular}{|c|c|c|c|}
\hline Study & $\begin{array}{l}\text { Level of } \\
\text { Analysis }\end{array}$ & Approach & Identified Antecedent(s) \\
\hline (Gunasekaran, 1999) & Business unit & $\mathrm{OM} / \mathrm{SCM}$ - Functional & $\begin{array}{l}\text { Rapid partnership, virtual enterprise, reconfigurability, } \\
\text { mass customization }\end{array}$ \\
\hline (Sharifi \& Zhang, 1999) & Firm & $\mathrm{OM} / \mathrm{SCM}$ - Functional & Agility drivers, agile capabilities, agility providers \\
\hline $\begin{array}{l}\text { (Christopher, 2000; Van Hoek et } \\
\text { al., 2001; Yusuf et al., 2004) }\end{array}$ & Firm & $\mathrm{OM} / \mathrm{SCM}$ - Holistic & $\begin{array}{l}\text { Network integration, process integration, virtual } \\
\text { integration, customer (market) sensitivity }\end{array}$ \\
\hline (Prater et al., 2001) & Firm & $\mathrm{OM} / \mathrm{SCM}$ - Holistic & $\begin{array}{l}\text { Sourcing flexibility \& speed, manufacturing flexibility } \\
\& \text { speed, delivery flexibility \& speed }\end{array}$ \\
\hline (Sambamurthy et al., 2003) & Firm & IS - Holistic & Knowledge reach/richness, process reach/richness \\
\hline $\begin{array}{l}\text { (Li et al., 2008; Swafford et al., } \\
2006 \text { ) }\end{array}$ & Firm & $\mathrm{OM} / \mathrm{SCM}$ - Holistic & $\begin{array}{l}\text { Manufacturing flexibility, procurement/sourcing } \\
\text { flexibility, distribution/logistics flexibility }\end{array}$ \\
\hline (Swafford et al., 2008) & Firm & $\mathrm{OM} / \mathrm{SCM}$ - Holistic & $\begin{array}{l}\text { Information technology integration, supply chain } \\
\text { flexibility }\end{array}$ \\
\hline (Braunscheidel \& Suresh, 2009) & Firm & $\mathrm{OM} / \mathrm{SCM}$ - Holistic & $\begin{array}{l}\text { Market orientation, learning orientation, external } \\
\text { flexibility, internal integration }\end{array}$ \\
\hline (Lee \& Xia, 2010) & Business unit & IS - Functional & Software team autonomy, software team diversity \\
\hline (Jacobs et al., 2011) & Business unit & $\mathrm{OM} / \mathrm{SCM}$ - Functional & Product modularity, process modularity \\
\hline (Gligor \& Holcomb, 2012a) & Firm & $\mathrm{OM} / \mathrm{SCM}$ - Holistic & $\begin{array}{l}\text { Supply chain coordination, supply chain cooperation, } \\
\text { Supply chain communication }\end{array}$ \\
\hline (Gligor \& Holcomb, 2012b) & Firm & $\mathrm{OM} / \mathrm{SCM}$ - Holistic & Information-supply chain logistics capabilities \\
\hline (Nijssen \& Paauwe, 2012) & Firm & HRM - Holistic & $\begin{array}{l}\text { Scalable workforce, fast organizational learning, highly } \\
\text { adaptable organizational structure }\end{array}$ \\
\hline (Blome et al., 2013) & Firm & $\mathrm{OM} / \mathrm{SCM}$ - Holistic & Supply side competence, demand side competence \\
\hline (Chakravarty et al., 2013) & Firm & IS - Holistic & IT competences \\
\hline (Liu et al., 2013) & Firm & IS - Holistic & Flexible IT infrastructure, IT assimilation \\
\hline $\begin{array}{l}\text { (Najafi Tavani, Sharifi, \& Ismail, } \\
\text { 2013) }\end{array}$ & Firm & $\mathrm{OM} / \mathrm{SCM}$ - Functional & Supplier involvement, absorptive capacity \\
\hline (Gligor et al., 2016) & Firm & $\mathrm{OM} / \mathrm{SCM}$ - Holistic & Market orientation, supply chain orientation \\
\hline$\overline{\text { Present study }}$ & Multilevel & HRM and SCM-Holistic & $\begin{array}{l}\text { Strategic orientations through managers' agile } \\
\text { capabilities and actions }\end{array}$ \\
\hline
\end{tabular}


Entrepreneurial and market orientation
Capacity to sense environmental opportunities and threats

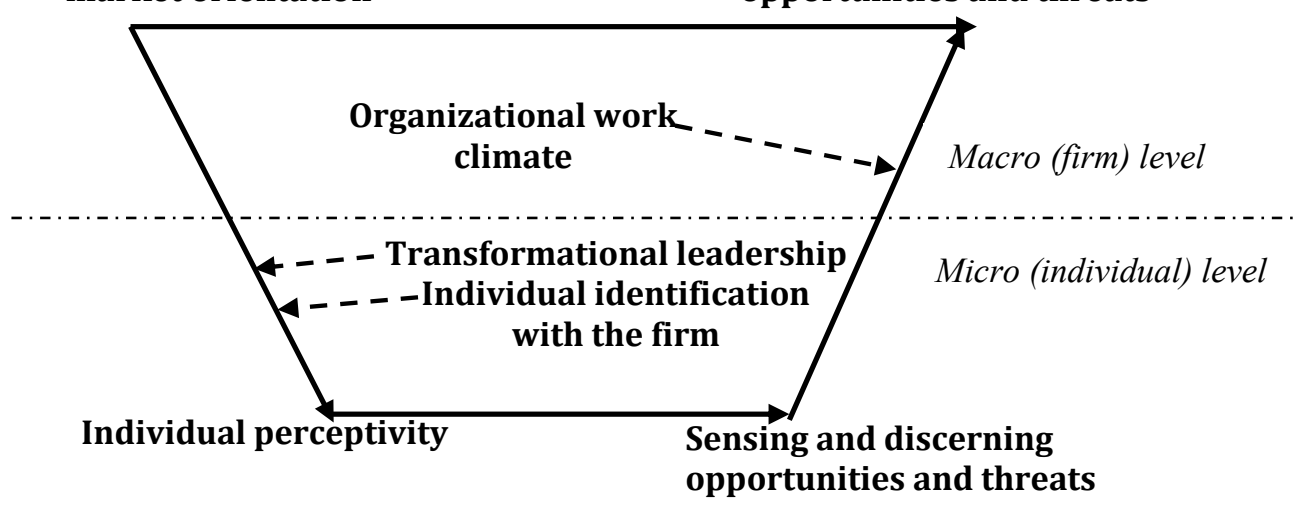

Figure 1. The firm's capacity to sense environmental opportunities and threats.

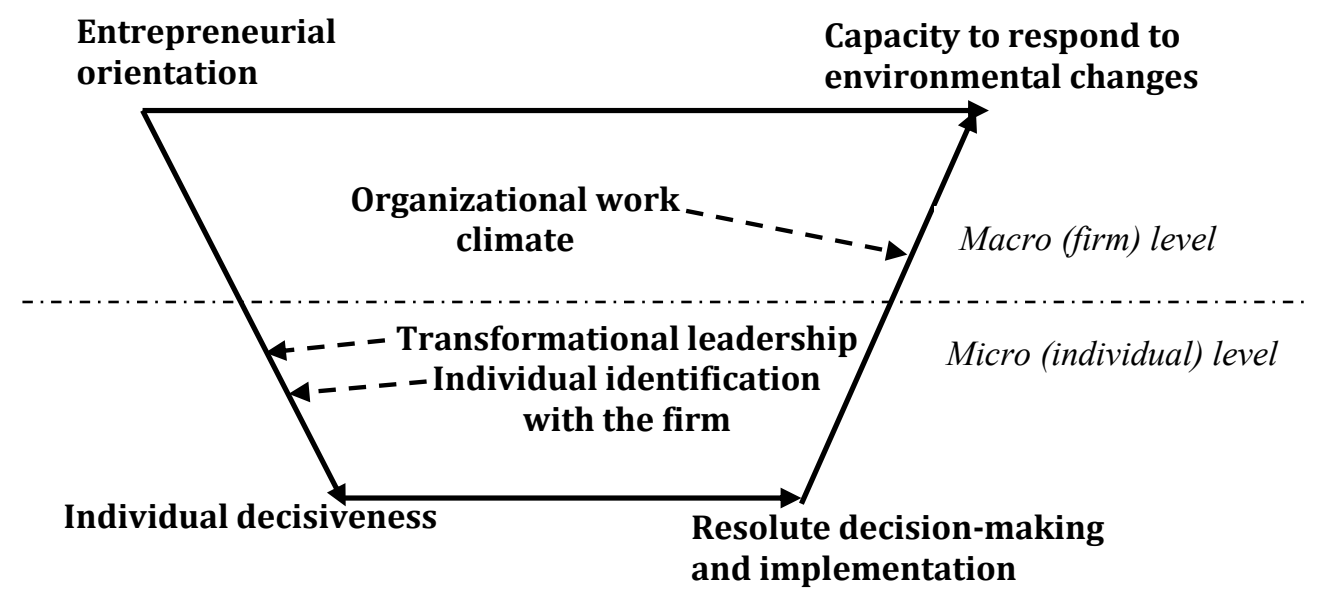

Figure 2. The firm's capacity to respond to environmental changes. 


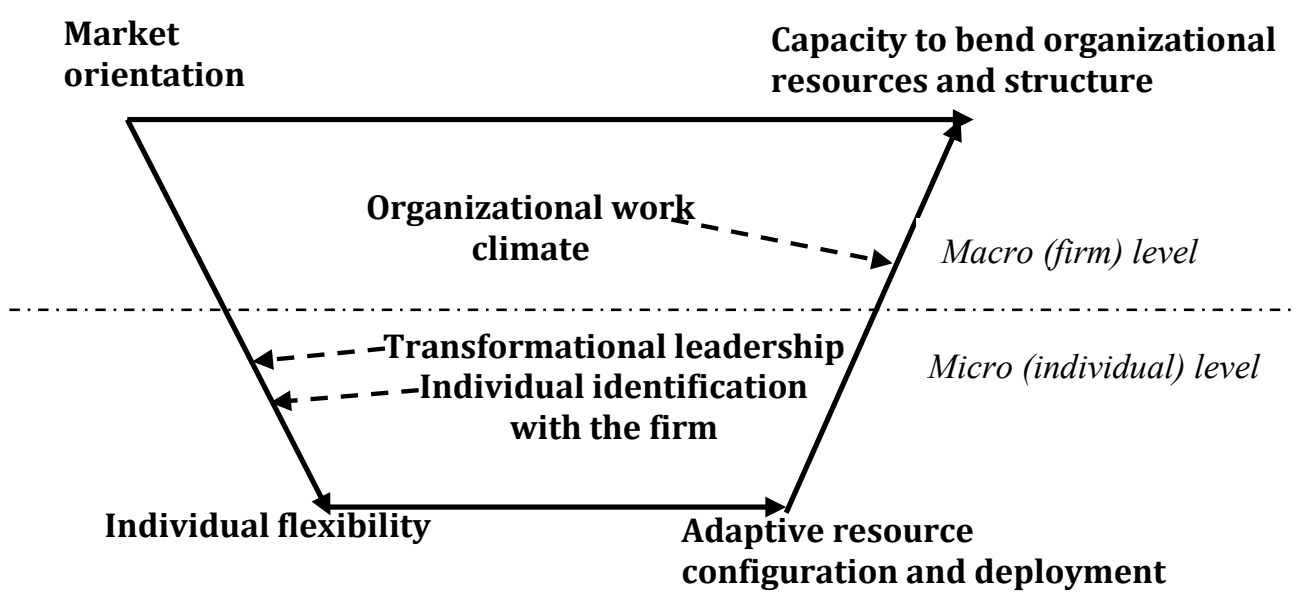

Figure 3. The firm's capacity to bend organizational resources and structure.

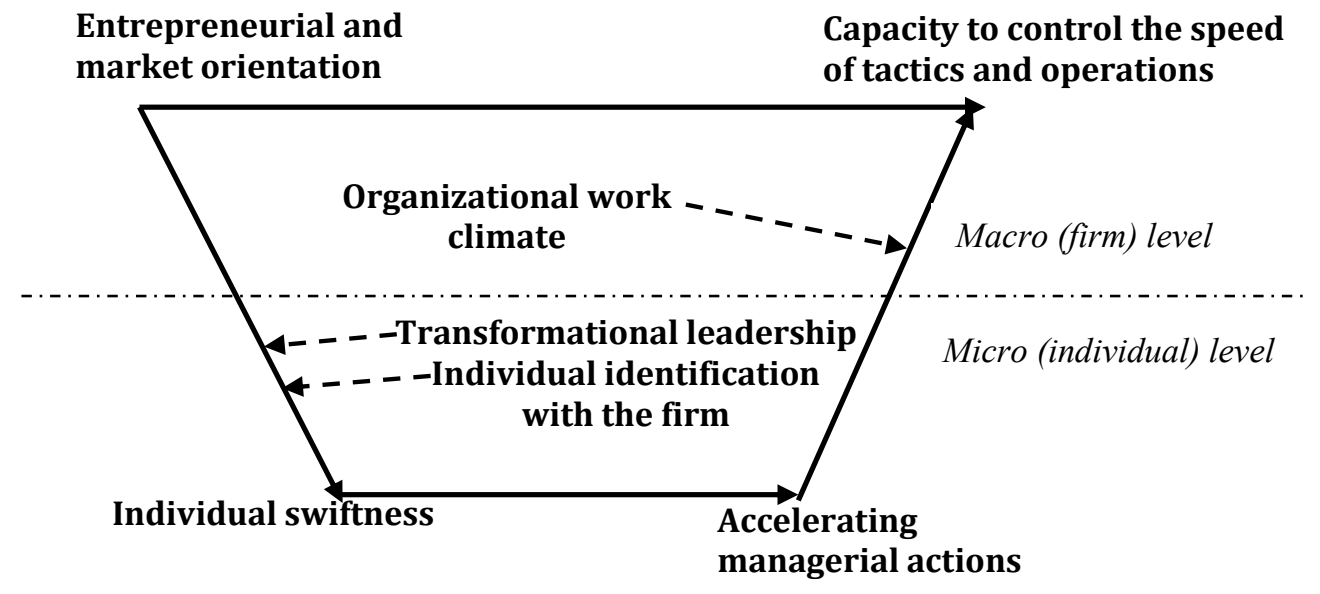

Figure 4. The firm's capacity to control the speed of tactics and operations. 


\section{References}

Alfes, K., Shantz, A. D., Truss, C. and Soane, E. C. (2013), "The link between perceived human resource management practices, engagement and employee behaviour: A moderated mediation model", International Journal of Human Resource Management, Vol. 24 No. 2, pp. 330-351.

Ashforth, B. E. and Mael, F. (1989), "Social identity theory and the organization", Academy of management review, Vol. 14 No. 1, pp. 20-39.

Augier, M. and Teece, D. J. (2007), "Dynamic capabilities and multinational enterprise: Penrosean insights and omissions", Management International Review, Vol. 47 No. 2, pp. 175-192.

Avolio, B. J., Zhu, W., Koh, W. and Bhatia, P. (2004), "Transformational leadership and organizational commitment: Mediating role of psychological empowerment and moderating role of structural distance", Journal of Organizational Behavior: The International Journal of Industrial, Occupational and Organizational Psychology and Behavior, Vol. 25 No. 8, pp. 951-968.

Bass, B. M. (1999), "Two decades of research and development in transformational leadership", European journal of work and organizational psychology, Vol. 8 No. 1, pp. 9-32.

Bass, B. M., Avolio, B. J., Jung, D. I. and Berson, Y. (2003), "Predicting unit performance by assessing transformational and transactional leadership", Journal of applied psychology, Vol. 88 No. 2, pp. 207.

Blome, C., Schoenherr, T. and Rexhausen, D. (2013), "Antecedents and enablers of supply chain agility and its effect on performance: A dynamic capabilities perspective", International Journal of Production Research, Vol. 51 No. 4, pp. 1295-1318.

Bowen, D. E. and Ostroff, C. (2004), "Understanding hrm-firm performance linkages: The role of the "strength" of the hrm system", Academy of management review, Vol. 29 No. 2, pp. 203-221.

Braunscheidel, M. J. and Suresh, N. C. (2009), "The organizational antecedents of a firm's supply chain agility for risk mitigation and response", Journal of Operations Management, Vol. 27 No. 2, pp. 119-140.

Brewer, M. B. and Gardner, W. (1996), "Who is this" we"? Levels of collective identity and self representations", Journal of personality and social psychology, Vol. 71 No. 1, pp. 83.

Cameron, K. S. and Quinn, R. E. (2011), Diagnosing and changing organizational culture: Based on the competing values framework, Jossey-Bass, San Francisco, CA.

Carmeli, A., Zivan, I., Gomes, E. and Markman, G. D. (2017), "Underlining micro socio-psychological mechanisms of buyer-supplier relationships: Implications for inter-organizational learning agility", Human Resource Management Review.

Chakravarty, A., Grewal, R. and Sambamurthy, V. (2013), "Information technology competencies, organizational agility, and firm performance: Enabling and facilitating roles", Information Systems Research.

Chen, C. J. and Lin, B. W. (2004), "The effects of environment, knowledge attribute, organizational climate, and firm characteristics on knowledge sourcing decisions", $R \& D$ Management, Vol. 34 No. 2, pp. 137-146.

Christopher, M. (2000), "The agile supply chain:: Competing in volatile markets", Industrial Marketing Management, Vol. 29 No. 1, pp. 37-44.

Coleman, J. S. (1990), Foundations of social theory, Belknap Press, Cambridge, MA \& London, UK.

Conboy, K. and Fitzgerald, B. (2004), "Toward a conceptual framework of agile methods: A study of agility in different disciplines", in Proceedings of the 2004 ACM Workshop on Interdisciplinary Software Engineering Research. ACM, Newport Beach, CA pp. 37-44.

De Ruiter, M., Lub, X., Jansma, E. and Blomme, R. J. (2016), "Psychological contract fulfillment and expatriate intrinsic career success: The mediating role of identification with the multinational corporation", International Journal of Human Resource Management, pp. 1-28.

Di Minin, A., Frattini, F., Bianchi, M., Bortoluzzi, G. and Piccaluga, A. (2014), "Udinese calcio soccer club as a talents factory: Strategic agility, diverging objectives, and resource constraints", European Management Journal, Vol. 32 No. 2, pp. 319-336. 
Doz, Y. and Kosonen, M. (2010), "Embedding strategic agility: A leadership agenda for accelerating business model renewal", Long Range Planning, Vol. 43 No. 2, pp. 370-382.

Dutton, J. E., Dukerich, J. M. and Harquail, C. V. (1994), "Organizational images and member identification", Administrative science quarterly, pp. 239-263.

Dyer, L. and Shafer, R. A. (2003), "Dynamic organizations: Achieving marketplace and organizational agility with people", in Peterson, R. S. and Mannix, E. A. (Eds.), Leading and managing people in the dynamic organization. Lawrence Erlbaum, Mahwah, NJ, pp. 7-40.

Eisenhardt, K. M. (1989), "Making fast strategic decisions in high-velocity environments", Academy of Management Journal, Vol. 32 No. 3, pp. 543-576.

Felin, T. and Foss, N. J. (2005), "Strategic organization: A field in search of micro-foundations", Strategic Organization, Vol. 3 No. 4, pp. 441.

Gabriel, A. S., Cheshin, A., Moran, C. M. and Van Kleef, G. A. (2016), "Enhancing emotional performance and customer service through human resources practices: A systems perspective", Human Resource Management Review, Vol. 26 No. 1, pp. 14-24.

Gaglio, C. M. and Katz, J. A. (2001), "The psychological basis of opportunity identification: Entrepreneurial alertness", Small Business Economics, Vol. 16 No. 2, pp. 95-111.

Garcia-Morales, V. J., Matias-Reche, F. and Hurtado-Torres, N. (2008), "Influence of transformational leadership on organizational innovation and performance depending on the level of organizational learning in the pharmaceutical sector", Journal of Organizational Change Management, Vol. 21 No. 2, pp. 188-212.

Gligor, D. M. (2013), "The concept of supply chain agility: Conceptualization, antecedents, and the impact on firm performance", Dissertation, The University of Tennessee, Knoxville, TN.

Gligor, D. M. and Holcomb, M. C. (2012a), "Antecedents and consequences of supply chain agility: Establishing the link to firm performance", Journal of Business Logistics, Vol. 33 No. 4, pp. 295308.

Gligor, D. M. and Holcomb, M. C. (2012b), "Understanding the role of logistics capabilities in achieving supply chain agility: A systematic literature review", Supply Chain Management: An International Journal, Vol. 17 No. 4, pp. 438-453.

Gligor, D. M., Holcomb, M. C. and Feizabadi, J. (2016), "An exploration of the strategic antecedents of firm supply chain agility: The role of a firm's orientations", International Journal of Production Economics, Vol. 179, pp. 24-34.

Gunasekaran, A. (1999), "Agile manufacturing: A framework for research and development", International Journal of production economics, Vol. 62 No. 1, pp. 87-105.

Gölgeci, I., Murphy, W. H. and Johnston, D. A. (2018), "Power-based behaviors in supply chains and their effects on relational satisfaction: A fresh perspective and directions for research", European Management Journal, Vol. 36 No. 2, pp. 278-287.

Hakala, H. (2011), "Strategic orientations in management literature: Three approaches to understanding the interaction between market, technology, entrepreneurial and learning orientations", International Journal of Management Reviews, Vol. 13 No. 2, pp. 199-217.

Hogg, M. A. and Terry, D. I. (2000), "Social identity and self-categorization processes in organizational contexts", Academy of management review, Vol. 25 No. 1, pp. 121-140.

Huo, B., Ye, Y., Zhao, X. and Shou, Y. (2016), "The impact of human capital on supply chain integration and competitive performance", International Journal of Production Economics, Vol. 178 No. Supplement C, pp. 132-143.

Jacobs, M., Droge, C., Vickery, S. K. and Calantone, R. (2011), "Product and process modularity's effects on manufacturing agility and firm growth performance", Journal of Product Innovation Management, Vol. 28 No. 1, pp. 123-137.

Jaw, B. S. and Liu, W. (2003), "Promoting organizational learning and self-renewal in Taiwanese companies: The role of hrm", Human Resource Management, Vol. 42 No. 3, pp. 223-241. 
Kao, R.-H. (2017), "The relationship between work characteristics and change-oriented organizational citizenship behavior: A multi-level study on transformational leadership and organizational climate in immigration workers", Personnel Review, Vol. 46 No. 8, pp. 1890-1914.

Kohli, A. K. and Jaworski, B. J. (1990), "Market orientation: The construct, research propositions, and managerial implications", Journal of Marketing, Vol. 54 No. 2, pp. 1-18.

Kuenzi, M. and Schminke, M. (2009), "Assembling fragments into a lens: A review, critique, and proposed research agenda for the organizational work climate literature", Journal of management, Vol. 35 No. 3, pp. 634-717.

Kwon, B., Farndale, E. and Park, J. G. (2016), "Employee voice and work engagement: Macro, meso, and micro-level drivers of convergence?", Human Resource Management Review.

Lee, G. and Xia, W. (2010), "Toward agile: An integrated analysis of quantitative and qualitative field data on software development agility", MIS Quarterly, Vol. 34 No. 1, pp. 87.

Lee, M. C. C. and Idris, M. A. (2017), "Psychosocial safety climate versus team climate: The distinctiveness between the two organizational climate constructs", Personnel Review, Vol. 46 No. 5, pp. 9881003.

Lengnick-Hall, C. A., Beck, T. E. and Lengnick-Hall, M. L. (2011), "Developing a capacity for organizational resilience through strategic human resource management", Human Resource Management Review, Vol. 21 No. 3, pp. 243-255.

Li, X., Chung, C., Goldsby, T. J. and Holsapple, C. W. (2008), "A unified model of supply chain agility: The work-design perspective", International Journal of Logistics Management, Vol. 19 No. 3, pp. 408-435.

Liu, H., Ke, W., Wei, K. K. and Hua, Z. (2013), "The impact of it capabilities on firm performance: The mediating roles of absorptive capacity and supply chain agility", Decision Support Systems, Vol. 54 No. 3, pp. 1452-1462.

Lumpkin, G. T. and Dess, G. G. (1996), "Clarifying the entrepreneurial orientation construct and linking it to performance", Academy of Management Review, Vol. 21 No. 1, pp. 135-172.

Min, S., Mentzer, J. and Ladd, R. (2007), "A market orientation in supply chain management", Journal of the Academy of Marketing Science, Vol. 35 No. 4, pp. 507-522.

Najafi Tavani, S., Sharifi, H. and Ismail, H. S. (2013), "A study of contingency relationships between supplier involvement, absorptive capacity and agile product innovation", International Journal of Operations \& Production Management, Vol. 34 No. 1, pp. 65-92.

Narver, J. C. and Slater, S. F. (1990), "The effect of a market orientation on business profitability", Journal of Marketing, Vol. 54 No. 4, pp. 20-35.

Nijssen, M. and Paauwe, J. (2012), "Hrm in turbulent times: How to achieve organizational agility?", International Journal of Human Resource Management, Vol. 23 No. 16, pp. 3315-3335.

O'malley, L., O'dwyer, M., Mcnally, R. C. and Murphy, S. (2014), "Identity, collaboration and radical innovation: The role of dual organisation identification", Industrial Marketing Management, Vol. 43 No. 8, pp. 1335-1342.

Ohana, M. (2014), "A multilevel study of the relationship between organizational justice and affective commitment: The moderating role of organizational size and tenure", Personnel Review, Vol. 43 No. 5, pp. 654-671.

Plonka, F. E. (1997), "Developing a lean and agile work force", Human Factors and Ergonomics in Manufacturing \& Service Industries, Vol. 7 No. 1, pp. 11-20.

Prater, E., Biehl, M. and Smith, M. A. (2001), "International supply chain agility-tradeoffs between flexibility and uncertainty", International Journal of Operations \& Production Management, Vol. 21 No. 5/6, pp. 823-839.

Rauch, A., Wiklund, J., Lumpkin, G. T. and Frese, M. (2009), "Entrepreneurial orientation and business performance: An assessment of past research and suggestions for the future", Entrepreneurship Theory and Practice, Vol. 33 No. 3, pp. 761-787.

Rhoades, L. and Eisenberger, R. (2002), "Perceived organizational support: A review of the literature", Journal of applied psychology, Vol. 87 No. 4, pp. 698. 
Rousseau, D. M. and Mclean Parks, J. (1993), "The contracts of individuals and organizations", Research in organizational behavior, Vol. 15, pp. 1-1.

Ryan, A. and O'malley, L. (2016), "The role of the boundary spanner in bringing about innovation in crosssector partnerships", Scandinavian Journal of Management, Vol. 32 No. 1, pp. 1-9.

Sambamurthy, V., Bharadwaj, A. and Grover, V. (2003), "Shaping agility through digital options: Reconceptualizing the role of information technology in contemporary firms", MIS Quarterly, Vol. 27 No. 2, pp. 237-263.

Sanders, K., Dorenbosch, L. and De Reuver, R. (2008), "The impact of individual and shared employee perceptions of hrm on affective commitment: Considering climate strength", Personnel Review, Vol. 37 No. 4, pp. 412-425.

Schweiger, S. A., Stettler, T. R., Baldauf, A. and Zamudio, C. (2019), "The complementarity of strategic orientations: A meta-analytic synthesis and theory extension", Strategic Management Journal.

Scott, S. G. and Lane, V. R. (2000), "A stakeholder approach to organizational identity", Academy of Management Review, Vol. 25 No. 1, pp. 43-62.

Shafer, R. A., Dyer, L., Kilty, J., Amos, J. and Ericksen, J. (2001), "Crafting a human resource strategy to foster organizational agility: A case study", Human Resource Management, Vol. 40 No. 3, pp. 197211.

Shamir, B., House, R. J. and Arthur, M. B. (1993), "The motivational effects of charismatic leadership: A self-concept based theory", Organization Science, Vol. 4 No. 4, pp. 577-594.

Sharifi, H. and Zhang, Z. (1999), "A methodology for achieving agility in manufacturing organisations: An introduction", International Journal of Production Economics, Vol. 62 No. 1-2, pp. 7-22.

Shub, A. N. and Stonebraker, P. W. (2009), "The human impact on supply chains: Evaluating the importance of "soft" areas on integration and performance", Supply Chain Management: An International Journal, Vol. 14 No. 1, pp. 31-40.

Swafford, P. M., Ghosh, S. and Murthy, N. (2008), "Achieving supply chain agility through it integration and flexibility", International Journal of Production Economics, Vol. 116 No. 2, pp. 288-297.

Swafford, P. M., Ghosh, S. and Murthy, N. N. (2006), "The antecedents of supply chain agility of a firm: Scale development and model testing", Journal of Operations Management, Vol. 24 No. 2, pp. $170-188$.

Teece, D. J. (2014), "A dynamic capabilities-based entrepreneurial theory of the multinational enterprise", Journal of International Business Studies, Vol. 45 No. 1, pp. 8-37.

Teece, D. J., Peteraf, M. A. and Leih, S. (2016), "Dynamic capabilities and organizational agility", California Management Review, Vol. 58 No. 4, pp. 13-35.

Tsourveloudis, N. C. and Valavanis, K. P. (2002), "On the measurement of enterprise agility", Journal of Intelligent \& Robotic Systems, Vol. 33 No. 3, pp. 329-342.

Van Dick, R., Wagner, U., Stellmacher, J. and Christ, O. (2004), "The utility of a broader conceptualization of organizational identification: Which aspects really matter?", Journal of Occupational and Organizational Psychology, Vol. 77 No. 2, pp. 171-191.

Van Hoek, R. I., Harrison, A. and Christopher, M. (2001), "Measuring agile capabilities in the supply chain", International Journal of Operations \& Production Management, Vol. 21 No. 1/2, pp. 126148.

Van Knippenberg, B. and Van Knippenberg, D. (2005), "Leader self-sacrifice and leadership effectiveness: The moderating role of leader prototypicality", Journal of Applied Psychology, Vol. 90 No. 1, pp. 25.

Van Knippenberg, D. and Schippers, M. C. (2007), "Work group diversity", Annu. Rev. Psychol., Vol. 58, pp. 515-541.

Wang, G., Oh, I.-S., Courtright, S. H. and Colbert, A. E. (2011), "Transformational leadership and performance across criteria and levels: A meta-analytic review of 25 years of research", Group \& organization management, Vol. 36 No. 2, pp. 223-270. 
Wei, L.-Q. and Lau, C.-M. (2005), "Market orientation, hrm importance and competency: Determinants of strategic hrm in Chinese firms", International Journal of Human Resource Management, Vol. 16 No. 10, pp. 1901-1918.

Wright, P. M. and Mcmahan, G. C. (2011), "Exploring human capital: Putting 'human' back into strategic human resource management", Human Resource Management Journal, Vol. 21 No. 2, pp. 93-104.

Yusuf, Y. Y., Gunasekaran, A., Adeleye, E. O. and Sivayoganathan, K. (2004), "Agile supply chain capabilities: Determinants of competitive objectives", European journal of operational research, Vol. 159 No. 2, pp. 379-392.

Zaccaro, S., Mumford, M., Marks, M., Connelly, M., Threlfall, K., Gilbert, J. and Fleishman, E. (1997), Cognitive and temperament determinants of army leadership, Management Research Institute, Bethesda, MD.

Zahra, S. A., Sapienza, H. J. and Davidsson, P. (2006), "Entrepreneurship and dynamic capabilities: A review, model and research agenda*", Journal of Management Studies, Vol. 43 No. 4, pp. 917-955. 